\section{Tai Chi Chuan. Revista de artes y estilos internos}

Directora: Teresa Rodríguez

Madrid: Luis Soldevila Ribelles, (2004- )

65-70 páginas. $21 \times 27 \mathrm{~cm}$. Ilustraciones

Trimestral • $6 € /$ ejemplar

I.S.S.N.: 1698-3173

\section{Disponible en:}

Luis Soldevila Ribelles.

C/ Verónica, 13 - $4^{\circ}$ Int. Izq.

28014 - Madrid (España).

Telfs.: +34914296872

E-mail: luiso@taichichuan.com.es

Web: www.taichichuan.com.es

\section{Revisión por Juan Pan González.}

Nos encontramos ante la primera revista en español dedicada exclusivamente a las artes internas (Tai Chi Chuan, Ba Gua Zhang, Xing Yi Chuan, etc.). Se trata de una publicación periódica de carácter trimestral, especializada y dirigida especialmente a todos los practicantes y profesores de las "artes internas" que quieran profundizar con seriedad en los diferentes conocimientos que rodean y se asocian a todas estas disciplinas.

Se trata de una iniciativa emprendida por Teresa Rodríguez y Luis Soldevila, ambos profundos conocedores de estas disciplinas. La idea surge hace casi tres años, con el propósito de dar a los artículos publicados un carácter serio y académico, en los que se refleje información fiable, que pueda ser aprovechada por cualquier persona que quiera profundizar en disciplinas como el Tai Chi, independientemente de la escuela a la que pertenezca.

Uno de los principios que guían la revista es la publicación de artículos originales, siempre y cuando sea posible. Para ello cuenta con el apoyo de una serie de colaboradores de importante prestigio en el ámbito nacional e internacional, como pueden ser Yang Jwing Ming, José Manuel Bonilla, David Conches, Eduardo Escudero, Raúl Fernández, Juanolo Rodríguez, Jordi Vilá, Li Chipang, Li Jing Ye, Loni Liebermann, Li Dong o Sam Masich, entre muchos otros, que por medio de traducciones, entrevistas o artículos propios, nos acercan un poco más al fascinante mundo de las artes marciales internas.

Cada número de la revista Tai Chi Chuan se estructura en varias secciones: editorial, sumario, la ventana del lector, noticias, convocatorias, artículos, entrevistas, anuncios publicitarios, libros, internet y glosario. El grueso de la revista lo componen los artículos, que tratan un amplio espectro de temas relacionados con las artes internas, como pueden ser metodología y didáctica, tai chi chuan, el proceso de aprendizaje, empuje de manos, qigong, el yin y el yang, filosofía o medicina china. Algunos de estos artículos son "Liu He Ba Fa: El boxeo de las seis armonías y los ocho métodos", por David Conches, "La conexión energética del Taiji”, por Fredy Cesar Erazo, "Diseñando una herramienta de enseñanza”, por Sam Masich, "Las trece posturas del Taiji de Wudang", por Jordi Vilá, "Neijing Tu: El paisaje interior", por Yang Jwing Ming, "Chen Zhenglei-Mas allá del cielo siempre hay otro cielo", por Luis Soldevila, "Aproximación teórica al Zhan Zhuang”, por Pedro Martín. Las personas que estén interesadas en conocer todos los artículos publicados hasta el momento, pueden consultarlos en su pagina web (www.taichichuan.com.es), donde además podrán leer alguno de ellos de forma totalmente gratuita.

La sección de libros recomienda en cada número una serie de libros de actualidad de notable interés, con comentarios de alguno de los colaboradores. Pero sin duda alguna la novedad de esta revista reside en la sección de internet, donde en cada publicación se ofrece una pequeña guía de páginas que aportan información de interés sobre las artes internas, lo que nos sirve para no perdernos por el mar de información que ofrece internet, muchas veces errónea o contradictoria.

Destacar también la sección de convocatorias, donde podemos encontrar un amplio y variado calendario de actividades, encuentros, seminarios, campeonatos, etc., donde cualquier persona interesada en aumentar su dominio y conocimiento de las artes internas, puede encontrar aquello que busca y se aproxime más a la forma personal de entender y practicar las artes marciales.

El formato de la revista es sencillo y elegante, acompañada de numerosas ilustraciones en blanco y negro, de gran calidad. Al final de cada publicación se encuentra un glosario en el que se explican los términos chinos que aparecen en cada número (de gran utilidad para quien se aproxime por primera vez al mundo interno de las artes marcia- les). Acompañando al significado, encontramos los caracteres chinos tradicionales y simplificados.

Ante el bombardeo indiscriminado de información que existe en internet y en distintos artículos, que son más un reclamo publicitario que artículos que traten con detenimiento alguno de los temas que puedan interesar a toda la comunidad marcial, me parece una suerte poder contar con la revista Tai Chi Chuan, ya que combina contenidos que profundizan en el ámbito de las artes y estilos internos, con información de actualidad relativa a noticias, encuentros y seminarios en nuestro país, y afortunadamente en español.

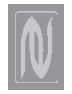

\section{Zen. Colección de escritos Zen y Pre-Zen}

Por Paul Reps y Nyogen Senzaki (Comps.)

Barcelona: Editorial Paidotribo, 2006.

172 páginas. $21,5 \times 15 \mathrm{~cm}$. Ilustraciones.

I.S.B.N.: 84-8019-877-X • $19 €$.

Disponible en:

Editorial Paidotribo

Polígono Les Guixeres

C/ de la Energía, 19-21

08915 Badalona (Barcelona - España)

Telf.: +34 933233311

Fax: + 34934535033

E-mail: paidotribo@paidotribo.com

http://www.paidotribo.com

\section{Revisión por Pablo Pereda González}

Zen. Colección de escritos Zen y Pre-Zen se erige en una de esas obras que, por los condicionantes que impone su propia esencia, es difícil de revisar. Una revisión exige criterios, juicios y por supuesto una valoración final. Si me dejase llevar por mi propia ética mi crítica se reduciría: "Mu".

No crean, he trasladado este principio hasta un conocido monje Zen y me ha felicitado por ello; pero entiendo que dejar un folio en blanco con la sola palabra "Mu" podría antojarse al menos un tanto incomprensible para el lector no habituado a esta disciplina. Por todo ello vaya una primera parte de mi revisión, esta que tan escuetamente escribo, hacia todos aquellos inmer- 